\title{
Perception of Non-radiation Healthcare Workers about Radiation in Cape Coast Metropolis, Ghana
}

\author{
Emmanuel Kobina Mesi Edzie ${ }^{1, *}$, Klenam Dzefi-Tettey ${ }^{2}$, Philip Narteh Gorleku ${ }^{1}$, Adu Tutu Amankwa ${ }^{3}$, \\ Ewurama Andam Idun ${ }^{4}$, Edmund Kwakye Brakohiapa ${ }^{5}$, Eric Aidoo ${ }^{6}$, Julius John Essoun ${ }^{1}$, \\ Frank Quarshie $^{7}$, Henry Kusodzi ${ }^{1}$, Abdul Raman Asemah ${ }^{1}$

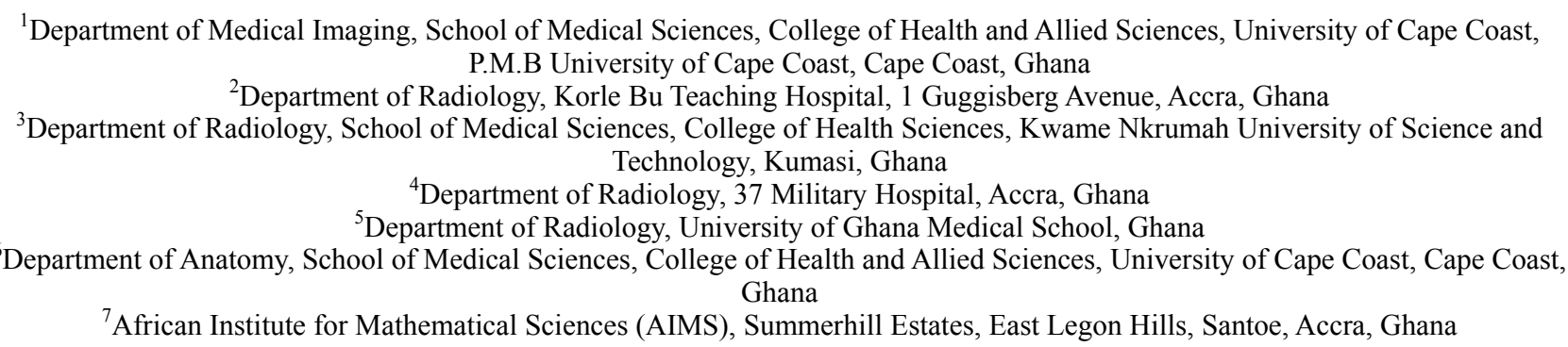

Received February 4, 2021; Revised March 12, 2021; Accepted April 9, 2021

\section{Cite This Paper in the following Citation Styles}

(a): [1] Emmanuel Kobina Mesi Edzie, Klenam Dzefi-Tettey, Philip Narteh Gorleku, Adu Tutu Amankwa, Ewurama Andam Idun, Edmund Kwakye Brakohiapa, Eric Aidoo, Julius John Essoun, Frank Quarshie, Henry Kusodzi, Abdul Raman Asemah, "Perception of Non-radiation Healthcare Workers about Radiation in Cape Coast Metropolis, Ghana," Universal Journal of Public Health, Vol. 9, No. 2, pp. 57 - 66, 2021. DOI: 10.13189/ujph.2021.090204.

(b): Emmanuel Kobina Mesi Edzie, Klenam Dzefi-Tettey, Philip Narteh Gorleku, Adu Tutu Amankwa, Ewurama Andam Idun, Edmund Kwakye Brakohiapa, Eric Aidoo, Julius John Essoun, Frank Quarshie, Henry Kusodzi, Abdul Raman Asemah (2021). Perception of Non-radiation Healthcare Workers about Radiation in Cape Coast Metropolis, Ghana. Universal Journal of Public Health, 9(2), 57 - 66. DOI: 10.13189/ujph.2021.090204.

Copyright $(2021$ by authors, all rights reserved. Authors agree that this article remains permanently open access under the terms of the Creative Commons Attribution License 4.0 International License

\begin{abstract}
The patient management team includes a wide category of healthcare workers, who in one way or the other interact to render services, including radiation-based services. It becomes imperative that every healthcare worker must have appreciable knowledge and opinions on radiation issues for effective service delivery. Hence, this study assesses the perception of non-radiation healthcare workers about radiation. This was a prospective questionnaire-based study involving 340 consented participants from four hospitals in Cape Coast. A stratified sampling method was employed for the number of respondents from each hospital. The responses obtained from Google Forms WhatsApp-administered questionnaires, were systematically selected to obtain the sample size. Data obtained were analysed with Statistical Package for Social Sciences (SPSS Inc., Chicago, IL version 20.0) and the results were presented in appropriate tables and charts. Statistical significance level was set at
\end{abstract}

$\mathrm{p} \leq 0.05$. The majority of the 340 participants were males. The average age was $32.26 \pm 7.618$ years. Nurses constituted majority $166(48.8 \%)$ of respondents, followed by allied health professionals. The knowledge of participants about radiation issues was high with over $65 \%$ of responses. There were statistically significant associations between gender, educational level, work experience and willingness to accept postings to radiology departments. We conclude that, the majority of non-radiation healthcare workers had a high level of knowledge about radiation issues. The perception of non-radiation healthcare workers was positive from suggestions and recommendations they offered.

Keywords Perception, Radiation, Cape Coast Metropolis, Non-radiation Healthcare Workers 


\section{Introduction}

The use of radiation has increased in recent years with an associated increase in exposure of patients and healthcare workers (HCWs) to radiation hazards from a variety of sources [1]. Radioactive materials and ionizing radiation, especially X-rays contribute the largest portion of radiation exposure to mankind [2]. Perhaps one of the best-known environmental sources of ionizing radiation is naturally occurring radon, which has consistently been associated with an increased risk for the development of caner of the lung [3]. Ionizing radiation has a widespread application for a variety of beneficial purposes [4]. The demand for diagnostic and therapeutic radiological procedures has increased in medicine, as X-ray imaging reports constitute about $30-50 \%$ of medical diagnosis [5]. Radiation based modalities like digital radiography/mammography and Computed Tomography Scan were reported in Ghana as the most available [6, 7]. Therefore, exposure of patients and radiation workers to ionizing radiation is inevitable, making the use of radiation in medical practice a source of exposing patients and radiation workers to the potential hazards of radiation [8]. Human systems such as reproductive, immune, hematopoietic and others are seriously affected by exposure to ionizing radiation. Also, leukemia, cataracts, and other malignant lesions are some other adverse effects of ionizing radiation $[9,10]$.

Awareness of and concerns over exposure to radiation and radiation-induced ionization have significantly increased in the past decade [11]. Public concerns regarding medical exposure to radiation are comparatively high, as the risks regarding this exposure are generally unclear [12]. The knowledge gap and perception about the dangers of radiation among radiation experts and the general public are substantially wide, partly because the mass media which is the source of information to the general public, and may distort and misinterpret technical knowledge about radiation [13]. The perception of individuals about the various types of radiation risks differs. Studies in the United States and other places have consistently reported a perception of a lower risk of radiation sources such as naturally occurring radon gas and medical X-rays to people, compared to nuclear waste and power, which is contrary to what radiation experts perceive [14]. There is inadequate knowledge about the dangers of exposure to radiation and the appropriate steps to minimize those hazards in some HCWs [15]. The patients, HCWs, and the general public have been progressively sensitized about radiation exposure issues whether from therapeutic and diagnostic examinations [16]. The understanding of the perception of radiation, the sentiments that influence the perception and the factors that influence these sentiments are necessary to effectively communicate health risk information. Various studies assessing the knowledge, attitude and practices of different HCWs working in the radiation units have shown different findings [17].

Although it is believed that non-radiation HCWs do not possess a good comprehension of radiation and its associated risks, few studies have investigated this assertion. There is a wide variation in the attitudes of patients undergoing diagnostic examination using ionizing radiation [18]. The acceptance of radiation-based examinations is closely influenced by the perception of patients about radiation issues [19]. Healthcare professionals are reliable sources of accurate information concerning radiation issues to their patients. Additionally, they play important roles in communicating the risks associated with radiation by sympathizing with and adequately dealing with patients' anxiety about radiation even though their also perceived by the public as sources of medical errors as reported in Australia by Kim et al [20, 21]. The aim of this study was to determine what the non-radiation HCWs knew about radiation, through the assessment of the following specific objectives;

- To determine the level of knowledge of non-radiation HCWs about radiation.

- To find out the thoughts and practices of non-radiation HCWs about radiation.

- To evaluate the attitude of non-radiation HCWs about radiation.

- To determine any possible associations between socio-demographic characteristics and perception of respondents.

\section{Methods}

\section{Study design}

This was a cross-sectional design, which considered non-radiation HCWs in four hospitals in the Cape Coast metropolis of the Central Region of Ghana from July to October 2020. All HCWs at the radiology department were excluded.

\section{Study site}

The study was conducted in four facilities in the Cape Coast metropolis: University of Cape Coast Hospital (UCCH), Cape Coast Teaching Hospital (CCTH), Ankaful General Hospital (AGH), and Cape Coast Metropolitan Hospital (CCMH). These are the facilities with X-ray departments. CCTH, which is the largest public health institution in Cape Coast Metropolis of the Central Region of Ghana, offers training and tertiary services. It is situated in the central part of Cape Coast. $\mathrm{UCCH}$ and $\mathrm{CCMH}$, both secondary healthcare institutions are located in the south-western side of Cape Coast and AGH at the north-western side of Cape Coast.

\section{Sampling and Data Collection}

The target population for the study was all non-radiation 
HCWs including doctors, nurses, allied health staffs and supportive staffs from all the four facilities. From the human resource records of these hospitals, there were about 1507, 293, 259, and 210 non-radiation HCWs from $\mathrm{CCTH}, \mathrm{UCCH}, \mathrm{CCMH}$ and $\mathrm{AGH}$ respectively giving a total of 2,269 . In estimating the sample size of a population of 10,000 or less, $10-30 \%$ of the total population is regarded as a good representation of the target population [22]. Based on that, $340(15 \%)$ of the total population was used as the total sample size for this study. With simple proportion, 226, 44, 39, and 31 respondents were sampled respectively from $\mathrm{CCTH}, \mathrm{UCCH}, \mathrm{CCMH}$ and $\mathrm{AGH}$ totaling 340 (Table 1).

Table 1. Sample Size Determination for each Site

\begin{tabular}{ccc}
\hline Facility & $\begin{array}{c}\text { Total Non-radiation } \\
\text { Healthcare } \\
\text { workers }\end{array}$ & $\begin{array}{c}\text { Number of participants at } \\
\text { each site(simple } \\
\text { proportion) }\end{array}$ \\
\hline CCTH & 1507 & 226 \\
UCCH & 293 & 44 \\
CCMH & 259 & 39 \\
AGH & 210 & 31 \\
Total & 2269 & 340 \\
\hline
\end{tabular}

Due to bans and restrictions in Ghana against public gatherings as a result of the Corona Virus Disease 2019 (Covid-19) pandemic, an online-based questionnaire was created in English, using Google Forms, to ensure participants' convenience and avoid face to face administration of the questionnaire. The questionnaire was pretested with 20 respondents from various facilities to check for reliability, clarity and validity. The questionnaire was grouped into three categories- socio-demographic characteristics; knowledge, attitude, thoughts and practices on radiation; suggestions to radiation HCWs based on respondents' perception and recommendations to healthcare authorities on radiation protection issues. Due to the heterogeneous nature of the non-radiation HCWs, the staffs were categorized under five professional groups namely; Administrative Staff, Doctors, Allied Health Staff, Nurses, and Pharmacy Staff and the link for the questionnaire was shared through their professional WhatsApp platforms. The purpose of the survey was clearly stated at the beginning of the questionnaire to thoroughly inform the participants. The inclusion and exclusion criteria were also indicated. Anonymity and confidentiality were guaranteed. Before responding to the survey, a section was provided at the beginning of the questionnaire for the participants to indicate as to which health facility they work at. Completion and submission of the questionnaire were indicated to imply an informed consent to participate in this study. All the responses obtained were stratified under the various health facilities where the participants work at. After which a systematic sampling (selecting every other response) was used to repeatedly select the responses until the targeted sample size for each facility was reached.

\section{Data analysis}

The data obtained was sorted, organized, edited, and coded. The analyses were done with IBM Statistical Package for Social Sciences (SPSS Inc., Chicago, IL version 20.0) for computation of descriptive statistics, including means, percentages, frequencies and standard deviations and presented in appropriate tables and charts. A chi-squared test was employed in determining the association between gender, educational level, profession, work experience and willingness to accept posting to the radiology department. Statistical significance for all tests was set at $\mathrm{p} \leq 0.05$.

\section{Ethical Considerations}

Ethical approval was issued by the CCTH Ethical Review Board with approval number [CCTHERC/EC/2020/058] and dated $2^{\text {nd }}$ June 2020. Anonymity and confidentiality were maintained throughout the study. The protocols of this study complied with the 1975 Declaration of Helsinki.

\section{Results}

\section{Characteristics of Participants}

Table 2. Characteristics of Participants

\begin{tabular}{|c|c|}
\hline Item & Count (\%) \\
\hline \multicolumn{2}{|l|}{ Age } \\
\hline Minimum & 18 \\
\hline Maximum & 60 \\
\hline Mean (SD) & $32.26(7.618)$ \\
\hline \multicolumn{2}{|l|}{ Gender } \\
\hline Male & $174(51.2 \%)$ \\
\hline Female & $166(48.8 \%)$ \\
\hline \multicolumn{2}{|c|}{ Educational Qualification } \\
\hline Certificate & $51(15.0 \%)$ \\
\hline Diploma & $102(30.0 \%)$ \\
\hline Bachelor's Degree & $143(42.1 \%)$ \\
\hline Masters & $37(10.9 \%)$ \\
\hline PHD & $5(1.5 \%)$ \\
\hline Others & $2(0.6 \%)$ \\
\hline \multicolumn{2}{|l|}{ Profession } \\
\hline Doctor & $57(16.8 \%)$ \\
\hline Nurse & $166(48.8 \%)$ \\
\hline Allied health Staff & $63(18.5 \%)$ \\
\hline Administrative Staff & $34(10.0 \%)$ \\
\hline Pharmacy Staff & $20(5.9 \%)$ \\
\hline \multicolumn{2}{|l|}{ Working Experience } \\
\hline 5 years or below & $189(55.6 \%)$ \\
\hline $6-10$ years & $83(24.4 \%)$ \\
\hline $11-15$ years & $26(7.6 \%)$ \\
\hline 16 - 20 years & $18(5.3 \%)$ \\
\hline 21 years and above & $24(7.1 \%)$ \\
\hline
\end{tabular}

$\mathrm{SD}=$ Standard Deviation 
Out of the 340 non-radiation HCWs surveyed, the majority $(51.2 \%)$ were males. The ages of the participants ranged from 18 to 60 years with the mean age $32.6 \pm 7.618$ years. Majority of the respondents $189(55.6 \%)$ had worked for 5 years or less. The characteristics of the respondents including their educational qualifications, professional categories and the number of years of working experience are shown in Table 2.

\section{Opinions of Respondents on Radiation}

We solicited for respondents' opinions about the types, the roles and the effects of radiation in human life. Most participants indicated that only two types of radiation (Ionizing and Non-ionizing) exist with the majority (76.2\%) of the participants concerned about the adverse effects of the former. Responses revealed that, majority $184(54.1 \%)$ of non-radiation HCWs would accept posting to the radiology department. However, most $297(87.4 \%)$ of the HCWs would discourage pregnant HCWs from accepting posting to the department. The health benefits and implications as per respondents' opinions are shown in Table 3.

Table 3. Opinions of Respondents on Radiation

\begin{tabular}{|c|c|c|}
\hline Item & Response & Count (\%) \\
\hline \multirow{3}{*}{$\begin{array}{l}\text { There are two types of radiation, ionizing and non-ionizing } \\
\text { radiation. }\end{array}$} & Yes & $228(67.1 \%)$ \\
\hline & No & $11(3.2 \%)$ \\
\hline & Don’t Know & $101(29.7 \%)$ \\
\hline \multirow{2}{*}{ If Yes, which one should you be concerned about? } & Ionizing & $215(94.3 \%)$ \\
\hline & Non-ionizing & $13(5.7 \%)$ \\
\hline \multirow{3}{*}{ Do you think radiation has any beneficial effects to mankind? } & Yes & $259(76.2 \%)$ \\
\hline & No & $30(8.8 \%)$ \\
\hline & Don’t Know & $51(15.0 \%)$ \\
\hline \multirow{3}{*}{ If Yes please state any you know of? } & Medical diagnosis and treatments & $221(85.7 \%)$ \\
\hline & Energy sources & $31(12.0 \%)$ \\
\hline & Industrial uses & $6(2.3 \%)$ \\
\hline \multirow{2}{*}{ Will you accept a posting to the radiology department? } & Yes & $184(54.1 \%)$ \\
\hline & No & $156(45.9 \%)$ \\
\hline \multirow{4}{*}{ If Yes, why? } & For better working conditions & $68(37.0 \%)$ \\
\hline & Acquisition of knowledge & $42(22.8 \%)$ \\
\hline & Services to humanity & $56(30.4 \%)$ \\
\hline & Interest in the field & $18(9.8 \%)$ \\
\hline \multirow{2}{*}{$\begin{array}{l}\text { Will you advise a pregnant woman to work in the radiology } \\
\text { department? }\end{array}$} & Yes & $43(12.6 \%)$ \\
\hline & No & $297(87.4 \%)$ \\
\hline \multirow{4}{*}{ If Yes, why? } & Speciality / duty & $8(18.6 \%)$ \\
\hline & It's safe due to availability of PPE & $29(67.4 \%)$ \\
\hline & Services to humanity & $3(7.0 \%)$ \\
\hline & No Suggestion & $3(7.0 \%)$ \\
\hline \multirow[b]{2}{*}{ If No why? } & Dangerous to the fetus & $220(74.1 \%)$ \\
\hline & $\begin{array}{l}\text { Harmful to the health of the pregnant } \\
\text { women }\end{array}$ & $77(25.9 \%)$ \\
\hline
\end{tabular}


Table 4. Association between Participant's Characteristics and whether they will accept posting to the radiology department

\begin{tabular}{|c|c|c|c|c|}
\hline \multirow[t]{2}{*}{ Item } & \multicolumn{2}{|c|}{$\begin{array}{c}\text { Will you accept a posting to the radiology } \\
\text { department? }\end{array}$} & \multirow[t]{2}{*}{$\chi^{2}$} & \multirow[t]{2}{*}{ P-value } \\
\hline & Yes & No & & \\
\hline \multicolumn{5}{|l|}{ Gender } \\
\hline Male & $110(63.2 \%)$ & $64(36.8 \%)$ & 11.887 & $0.001^{*}$ \\
\hline Female & $74(44.6 \%)$ & $92(55.4 \%)$ & & \\
\hline \multicolumn{5}{|c|}{ Educational Qualification } \\
\hline Certificate & $19(37.3 \%)$ & $32(62.7 \%)$ & & \\
\hline Diploma & $51(50 \%)$ & $51(50 \%)$ & & \\
\hline Bachelor's Degree & $89(62.2 \%)$ & $54(37.8 \%)$ & 14.002 & $0.016^{*}$ \\
\hline Masters & $22(59.5 \%)$ & $15(40.5 \%)$ & & \\
\hline PHD & $3(60.0 \%)$ & $2(40.0 \%)$ & & \\
\hline Others & $0(0.0 \%)$ & $2(100.0 \%)$ & & \\
\hline \multicolumn{5}{|l|}{ Profession } \\
\hline Doctor & $33(57.9 \%)$ & $24(42.1 \%)$ & & \\
\hline Nurse & $80(48.2 \%)$ & $86(51.8 \%)$ & & \\
\hline Allied health Staff & $41(65.1 \%)$ & $22(34.9 \%)$ & 8.437 & 0.077 \\
\hline Administrative Staff & $16(47.1 \%)$ & $18(30.0 \%)$ & & \\
\hline Pharmacy Staff & $14(70.0 \%)$ & $6(30.0 \%)$ & & \\
\hline \multicolumn{5}{|l|}{ Working Experience } \\
\hline 5 years or below & $89(47.1 \%)$ & $100(52.9 \%)$ & & \\
\hline $6-10$ years & $50(60.2 \%)$ & $33(39.8 \%)$ & & \\
\hline $11-15$ years & $20(76.9 \%)$ & $6(23.1 \%)$ & 12.998 & $0.011^{*}$ \\
\hline $16-20$ years & $13(72.2 \%)$ & $5(27.8 \%)$ & & \\
\hline 21 years and above & $12(50.0 \%)$ & $12(50.0 \%)$ & & \\
\hline
\end{tabular}

*Statistically significant. Chi-squared $(\chi 2)$ was used to examine the relationship between gender, educational qualification, profession, working experience and the willingness to accept posting to the radiology department. $\mathrm{P} \leq 0.05$ is statistically significant.

A Chi squared analysis revealed that, a significant proportion $110(63.2 \%)$ of those willing to accept posting to the radiology department were males $(\mathrm{p}=0.001)$. Educational qualification $(\mathrm{p}=0.016)$ and working experience $(\mathrm{p}=0.011)$ also showed a significant correlation with willingness to accept posting to the radiology department. However, the willingness to accept posting to the radiology department was not significantly associated with the professional category to which the HCWs belonged $(\mathrm{p}=0.077)$ as shown in Table 4 .

\section{General Knowledge on Radiation}

An assessment of respondents understanding on radiation was done on a five point Likert scale. Majority $(88.9 \%)$ agreed and strongly agreed that, the use of lead apron and other protective equipment can reduce the harmful effect of radiation. The non-radiation HCWs also disagreed that the exposure to ionizing radiation has no effects on the human body. Other findings are also presented in Table 5. 
Table 5. General Knowledge on Radiation (Protection/Safety, Harmful effects and Benefits)

\begin{tabular}{|c|c|c|c|c|c|}
\hline \multirow[t]{2}{*}{ Items } & \multicolumn{5}{|c|}{ Count (\%) } \\
\hline & SA & A & $\mathrm{N}$ & $\mathrm{D}$ & SD \\
\hline The sun is a source of radiation. & $203(59.7 \%)$ & $113(33.2 \%)$ & $15(4.4 \%)$ & $4(1.2 \%)$ & $5(1.5 \%)$ \\
\hline $\begin{array}{l}\text { Ionizing radiation may cause } \\
\text { cancer or other blood diseases } \\
\text { such as leukemia, or death. }\end{array}$ & $178(52.4 \%)$ & $121(35.6 \%)$ & $32(9.4 \%)$ & $9(2.6 \%)$ & $0(0.0 \%)$ \\
\hline $\begin{array}{l}\text { Ionizing radiation may cause } \\
\text { sterility. }\end{array}$ & $135(39.7 \%)$ & $129(37.9 \%)$ & $65(19.1 \%)$ & $10(2.9 \%)$ & $1(0.3 \%)$ \\
\hline $\begin{array}{l}\text { Wearing lead apron and other } \\
\text { protective equipment can reduce } \\
\text { the harmful effect of radiation. }\end{array}$ & $193(56.8 \%)$ & $109(32.1 \%)$ & $23(6.8 \%)$ & $10(2.9 \%)$ & $5(1.5 \%)$ \\
\hline $\begin{array}{l}\text { Ionizing radiation may cause } \\
\text { genetic mutations or behavioral } \\
\text { damages }\end{array}$ & $144(42.4 \%)$ & $118(34.7 \%)$ & $70(20.6 \%)$ & $6(1.8 \%)$ & $2(0.6 \%)$ \\
\hline $\begin{array}{l}\text { Ionizing radiation may cause } \\
\text { baldness and skin burns. }\end{array}$ & $107(31.5 \%)$ & $130(38.2 \%)$ & $84(24.7 \%)$ & $14(4.1 \%)$ & $5(1.5 \%)$ \\
\hline $\begin{array}{l}\text { Exposure to ionizing radiation } \\
\text { has no effects on the human body. }\end{array}$ & $22(6.5 \%)$ & $21(6.1 \%)$ & $50(14.7 \%)$ & $93(27.4 \%)$ & $154(45.3 \%)$ \\
\hline $\begin{array}{l}\text { Ionizing radiation is a secure } \\
\text { source of energy. }\end{array}$ & $34(10.0 \%)$ & $83(24.4 \%)$ & $132(38.8 \%)$ & $51(15.0 \%)$ & $40(11.8 \%)$ \\
\hline $\begin{array}{l}\text { The effect of radiation is more } \\
\text { severe on the fetus and growing } \\
\text { child. }\end{array}$ & $181(53.2 \%)$ & $97(28.5 \%)$ & $41(12.1 \%)$ & $14(4.1 \%)$ & $7(2.1 \%)$ \\
\hline
\end{tabular}

SA - Strongly Agree, A - Agree, N - Neutral, D - Disagree, SD - Strongly Disagree

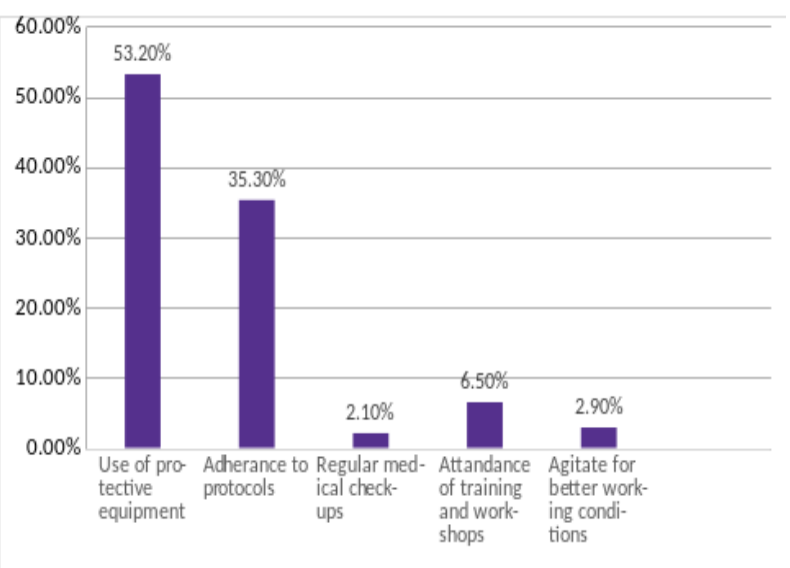

Figure 1. Suggestions to the radiology Staff based on respondents' perception.

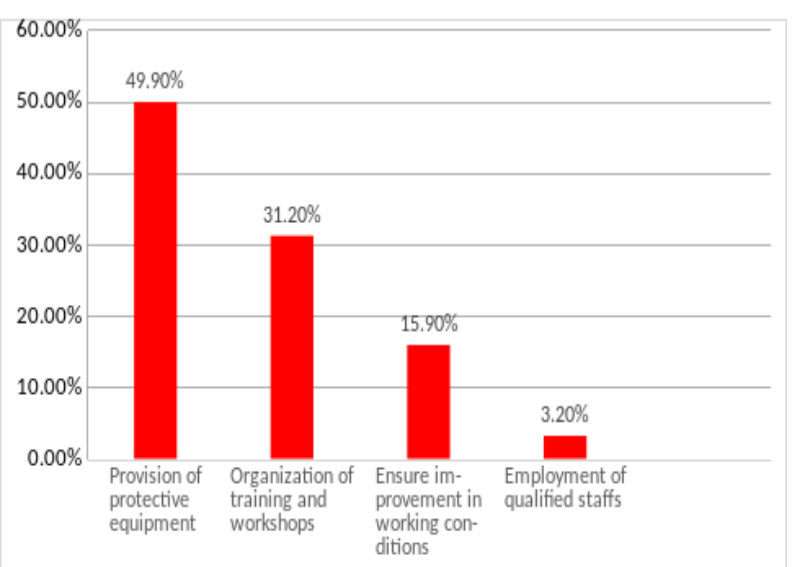

Figure 2. Recommendations to the hospital management/Ministry of health on radiation protection issues

\section{Suggestions and Recommendation}

For the staff of the radiology department, most respondents suggested the frequent use of protective equipment $(53.2 \%)$ and adherence to protocols $(35.3 \%)$. Majority recommended adequate supply of these protective equipment (49.9\%), either by the hospital management or Ministry of health. Other suggestions and recommendations are illustrated in Figures 1 and 2 respectively.

\section{Discussion}

The central idea on which the study was conducted was to determine the level of knowledge of non-radiation HCWs on radiation in medical practice. The results of this study showed that, most participants had a high level of knowledge on radiation in terms of the types, benefits and effects (Table 3). In contrast, a study by Chun-sing et al., and others showed that physicians and interns had poor knowledge of radiation related to radiological imaging [23-31]. These studies considered all HCWs including radiologists. But in our study, all HCWs apart from those from the radiology department were recruited. However, in those studies, they found that, the level of knowledge of the radiologists who in reality should have a higher level of knowledge on radiation related issues was unsatisfactory.

The knowledge and awareness regarding safety issues on ionizing radiation were high in our study (Table 5). But numerous studies have highlighted the low level of awareness among HCWs regarding their understanding of 
ionizing radiation. The lack of knowledge on the safety issues associated with ionizing radiation in other reports is in contrast to our findings [32-34]. This means non-radiation HCWs will be able to efficiently protect themselves or their patients against ionizing radiation, in compliance with the principle of as low as reasonably achievable (ALARA) routinely used in medical imaging should they find themselves in the radiology department [35]. This explains why the majority (54.1\%) of the respondents in our study were willing to accept posting to the radiology department given the opportunity. Furthermore, we found out that acceptance of posting to the radiology department had significant associations with the gender of participants, educational qualification and work experience as those willing to accept posting to the radiology department had practised for more than five years, which could be a factor for the high level of awareness of ionizing radiation (Table 4). When asked whether they would advise pregnant women to work at the radiology department, the majority (87.4\%) answered "No" whilst 12.6\% answered "Yes". Both sides gave convincing reasons to justify their responses (Table 3). The authors assert that fear of radiation is highly entrenched, which can negatively affect patient care. Systematic education about radiation is therefore needed to address unnecessary anxiety [36]. The degree of knowledge regarding the use of personal protective equipment (PPE) was high with $88.9 \%$ of the respondents appreciating the need for such equipment (Table 5). A study among nurses working in a radiology department in Kuwait revealed that the majority of nurses had low knowledge of radiation protection protocols and risk of radiation [37]. Takanami et al., investigated the need to protect against radiation exposure and reported that in response to the question, "How do you protect yourself against radiation exposure?", nurses responded with, "I do not approach the room where radiation is irradiated" and "I do not care for patients who undergo radiation treatment or diagnostic tests because a radiological technologist cares for the patient" [38]. Likewise, in Ghana, a study on nurses' knowledge on ionizing radiation reported inadequate knowledge in majority of nurses and erroneous beliefs about radiation sources and protection against radiation [39].

The risk of radiation has long been recognized as a major public health burden because of its potential for acute and chronic health effects [40]. Recommendations to the health authorities on radiation protection issues and suggestions to the radiology staff obtained from the non-radiation HCWs were similar (Figures 1, 2). The majority of participants recommended provision of adequate protective equipment and suggested strict adherence to safety protocols as a means of reducing their exposure to radiation. Other studies found that some operating rooms lack protective equipment to protect $\mathrm{HCW}$ s from the adverse effects of radiation. A recent study in South Africa among interventionalists found inconsistent use of PPE and their existence were not always available [41]. Similarly, in a study in Trinidad, the authors reported $80 \%$ lack of availability of PPE such as thyroid shields and lead aprons, even though there was constant exposure to ionizing radiation from various sources $[42,43]$. The next most common recommendation proposed by the respondents from our study on radiation protection issues was to provide training and education through the organization of workshops. In a study among health professionals in Trinidad, it was startling that the simple knowledge regarding radiation exposure and safe machine usage was insufficient among participants [42]. Szarmach et al., in 2015 reported that HCWs should undergo periodic training regarding radiological protection irrespective of their position and length of service [44].

\section{Limitation}

A notable limitation of this study included the fact that the responses obtained were selected alternately based on the order in which they appeared. This had the potential to skew the responses. Also the sample size considered for this study was relatively lower, hence, further studies with larger sample sizes may be required in future.

\section{Conclusions}

The observations made in this study suggest that, the majority of non-radiation HCWs had a high level of knowledge and awareness about radiation and its types, effects of ionizing radiation and radiation safety issues. This implies that, the non-radiation HCWs will be able to efficiently protect themselves or their patients against ionizing radiation should they find themselves in the radiology department in conformity with ALARA principle. The perception of non-radiation $\mathrm{HCWs}$ was generally positive since they offered tangible suggestions and recommendations regarding radiation protection issues to radiation workers and their willingness to accept posting to the radiology department which is laudable. The acceptance of posting to the radiology department was significantly associated with gender, educational status and working experience, this can be a valuable guide to the human resource departments of healthcare facilities during recruitment and/or poaching of healthcare workers.

\section{Authors' Contribution}

Emmanuel Kobina Mesi Edzie, Klenam Dzefi-Tettey, Philip Narteh Gorleku, Adu Tutu Amankwa and Ewurama Andam Idun made substantial inputs to the conception, design, implementation, drafting of the manuscript, 
revising and approving the manuscript for publication Edmund Kwakye Brakohiapa, Eric Aidoo, Julius John Essoun, Frank Quarshie, Henry Kusodzi and Abdul Raman Asemah all made significant contributions in designing, implementing, analyzing, literature searches, revising and approving the manuscript for publication.

\section{Data Availability}

Data used to support the findings of this study may be obtained upon request to the Head of the Research Unit of the Cape Coast Teaching Hospital. Postal address is as follows: P.O. Box CT I363, Cape Coast, Ghana. E-mail is ccthresearch@gmail.com.

\section{Funding}

No external funding was secured.

\section{Conflict of Interest}

None to declare.

\section{Acknowledgements}

We are grateful to all the non-radiation healthcare workers who graciously responded to our questionnaire. Appreciation to the medical directors of the four health facilities (CCTH, UCCH, CCMH and AGH).

\section{REFERENCES}

[1] Awosan KJ, Ibrahim MT, Saidu SA, Ma'aji SM, Danfulani M, Yunusa EU, Ikhuenbor DB, Ige TA. Knowledge of radiation hazards, radiation protection practices and clinical profile of health workers in a teaching hospital in Northern Nigeria. J Clin Diagn Res. 2016 Aug;10(8):LC07. https://doi.org/10.7860/JCDR/2016/20398.8394

[2] World Health Organisation. Ionizing radiation, health effects and protective measures. April, 2016. Retrieved from https://www.who.int/news-room/fact-sheets/detail/ionizingradiation-health-effects-and-protective-measures on 20th November, 2020.

[3] D. Hauri, B. Spycher, A. Huss et al., "Domestic radon exposure and risk of childhood cancer: a prospective census-based cohort study," Environ Health Perspect, vol. 121, no. 10, pp. 1239-1244, 2013. https://doi.org/10.1289/e hp. 1306500

[4] Niu SH. Safe work information note series. Radiation Protection of Workers. Geneva, Switzerland: International Labour Organization (ILO); 2011. Retrieved from https://www.ilo.org/wcmsp5/groups/public/---ed_protect/--- protrav/---safework/documents/publication/wcms 154238.p $\mathrm{df}$

[5] Herrmann TL, Fauber TL, Gill J, Hoffman C, Orth DK, Peterson PA, Prouty RR, Woodward AP, Odle TG. Best practices in digital radiography. Radiol Technol. 2012 Sep 1;84(1):83-9.

[6] Edzie EKM, Dzefi-Tettey K, Gorleku PN, Idun EA, Osei B, Cudjoe $\mathrm{O}$, et al. Application of information and communication technology in radiological practices: a cross-sectional study among radiologists in Ghana. J Glob Health Reports. 2020; 4:e2020046. https://doi.org/10.29392 /001c. 13060

[7] Edzie EKM, Gorleku PN, Dzefi-Tettey K, Idun EA, Amankwa AT, Aidoo E, Asemah AR, Kusodzi H. Incidence rate and age of onset of first stroke from CT scan examinations in Cape Coast metropolis. Heliyon. $2021 \mathrm{Feb}$ $1 ; 7(2): \mathrm{e} 06214$ https://doi.org/10.1016/j.heliyon.2021.e06214

[8] Briggs-Kamara MA, Okoye PC, Omubo-Pepple VB. Radiation safety awareness among patients and radiographers in three hospitals in Port Harcourt. Am J Sci Ind Res. 2013; 4: 83-8.https://doi.org/10.5251/ajsir.2013.4. 1.83 .88

[9] Little MP. Ionising radiation in the workplace. BMJ. 2015 Oct 20; 351():h5405. https://doi.org/10.1136/bmj.h5405

[10] Stewart FA, Akleyev AV, Hauer-Jensen M, Hendry JH, Kleiman NJ, Macvittie TJ, Aleman BM, Edgar AB, Mabuchi K, Muirhead CR, Shore RE. ICRP publication 118: ICRP statement on tissue reactions and early and late effects of radiation in normal tissues and organs-threshold doses for tissue reactions in a radiation protection context. Annals of the ICRP. 2012 Feb 1;41(1-2):1-322. https://doi.org/10.101 6/j.icrp.2012.02.001

[11] Ricketts ML, Baerlocher MO, Asch MR, Myers A. Perception of radiation exposure and risk among patients, medical students, and referring physicians at a tertiary care community hospital. Can AssocRadiol J. 2013 Aug; 64(3):208-12. https://doi.org/10.1016/j.carj.2012.05.002

[12] Itaki C, Tomisawa T, Ohgino A, Aizu K. Perception of radiation risk in health sciences students with different majors. Radiation Emergency Medicine. 2012;1(1):79-83.

[13] Evans KM, Bodmer J, Edwards B, Levins J, O'Meara A, Ruhotina M, Smith R, Delaney T, Hoffman-Contois R, Boccuzzo L, Hales H. An exploratory analysis of public awareness and perception of ionizing radiation and guide to public health practice in Vermont. J Environ Public Health. 2015 Apr 28;2015. https://doi.org/10.1155/2015/476495

[14] Slovic P. The perception gap: Radiation and risk. Bull At Sci. 2012 May; 68(3):67-75. https://doi.org/10.1177/009634021 2444870

[15] Alavi SS, Dabbagh ST, Abbasi M, Mehrdad R. Medical radiation workers' knowledge, attitude, and practice to protect themselves against ionizing radiation in Tehran Province, Iran. J Educ Health Promot. 2017;6. https://doi.org/10.4103/jehp.jehp_126_15

[16] Freudenberg LS, Beyer T. Subjective perception of radiation risk. J. Nucl. Med. 2011 Dec 1;52:29S.https://doi.org/10.29 67/jnumed.110.085720 
[17] Behzadmehr R, Doostkami M, Sarchahi Z, Saleh LD, Behzadmehr R. Radiation protection among health care workers: knowledge, attitude, practice, and clinical recommendations: a systematic review. Rev. Environ. Health. 2020 Sep 7;1(ahead-of-print). https://doi.org/10.151 5/reveh-2020-0063

[18] Sweetman SJ, Bernard J. Patient Knowledge and Perception of Radiation Risk in Diagnostic Imaging: A Cross-Sectional Study. J. Patient Exp. 2020 Feb;7(1):110-5.https://doi.org/1 $0.1177 / 2374373518825118$

[19] Busey JM, Soine LA, Yager JR, Choi E, Shuman WP. Patient knowledge and understanding of radiation from diagnostic imaging. JAMA Intern. Med. 2013 Feb 11;173(3):239-41.

https://doi.org/10.1001/2013.jamainternmed.1013

[20] Ashley Brooks. What Healthcare Workers Need to Know About Radiation Effects; 2016. Retrieved from https://www.rasmussen.edu/degrees/health-sciences/blog/ra diation-effects-on-healthcare-workers/ on 10th December, 2020 .

[21] Kim JA, Terry D, Jang S, Nguyen H, Gilbert J, Cruickshank M. Public perception of medical errors: experiences and risks shared in Australia. Universal Journal of Public Health. 2020;8(1):35-41.

https://doi.org/10.13189/ujph.2020.080104

[22] Mugenda, A., \&amp; M. Research Methods: Quantitative and Qualitative Approaches. Acts Press Publishers. 2009; https://doi.org/10.1109/LCN.2003.1243207

[23] Dellie ST, Admassie D, Ewnetu Y. An assessment of final-year medical students and interns awareness of radiation exposure to common diagnostic imaging procedures. Advances in Radiology. 2014;2014. https://doi.org/10.1155/2014/426909

[24] Chun-sing W, Bingsheng H, Ho-kwan S, Wai-lam W, Ka-ling Y, Tiffany CY. A questionnaire study assessing local physicians, radiologists and interns' knowledge and practice pertaining to radiation exposure related to radiological imaging. Eur. J. Radiol. 2012 Mar 1;81(3):e264-8. https://doi.org/10.1016/j.ejrad.2011.02.022

[25] Keijzers GB, Britton CJ. Doctors' knowledge of patient radiation exposure from diagnostic imaging requested in the emergency department. Med. J. Aust. 2010 Oct:193(8):450-3.

https://doi.org/10.5694/j.1326-5377.2010.tb03998.x

[26] Zewdneh D, Dellie ST, Ayele T. A study of knowledge \& awareness of medical doctors towards radiation exposure risk at TikurAnbessa specialized referral and teaching hospital, Addis Ababa, Ethiopia. IOSR J Pharm Biol Sci. 2012;2(4):2278-3008.

[27] Masoumbeigi M, Mohseni M, Akbari H. Knowledge of medical interns and radiology residents, students, and staff about the radiation dose received by patients in different imaging methods. Journal of Mazandaran University of Medical Sciences. 2017 Jan 10; 26(144):230-9. http://jmums.mazums.ac.ir/article-1-9264-en.html

[28] DivrikGökçe S, Gökçe E, Coşkun M. Radiology residents' awareness about ionizing radiation doses in imaging studies and their cancer risk during radiological examinations. Korean J Radiol. 2012 Apr 1;13(2):202-9.https://doi.org/10
$.3348 /$ kjr.2012.13.2.202

[29] Günalp M, Gülünay B, Polat O, Demirkan A, Gürler S, Akkaş $\mathrm{M}$, Aksu NM. Ionising radiation awareness among resident doctors, interns, and radiographers in a university hospital emergency department. Radiol Med. 2014 Jun 1;119(6):440-7. https://doi.org/10.1007/s11547-013-0374-8

[30] Campanella F, Rossi L, Giroletti E, Micheletti P, Buzzi F, Villani S. Are physicians aware enough of patient radiation protection? Results from a survey among physicians of Pavia District-Italy. BMC Health Serv. Res. 2017 Dec 1;17(1):406. https://doi.org/10.1186/s12913-017-2358-1

[31] Singh P, Aggarwal S, Kapoor AM, Kaur R, Kaur A. A prospective study assessing clinicians attitude and knowledge on radiation exposure to patients during radiological investigations. J Nat Sc Biol Med. 2015 Jul;6(2):398. https://doi.org/10.4103/0976-9668.160019

[32] Yurt A, Çavuşoğlu B, Günay T. Evaluation of awareness on radiation protection and knowledge about radiological examinations in healthcare professionals who use ionized radiation at work. Mol Imaging RadionuclTher. 2014 Jun;23(2):48. https://doi.org/10.4274/mirt.00719

[33] Bordoli SJ, Carsten III CG, Cull DL, Johnson BL, Taylor SM. Radiation safety education in vascular surgery training. J Vasc Surg. 2014 Mar 1;59(3):860-4. https://doi.org/10.10 16/j.jvs.2013.10.085

[34] Kada S. A study of general practitioners' knowledge of ionizing radiation from diagnostic imaging examinations. Qual Prim Care. 2010;18(6):391-7.

[35] Siegel JA, McCollough CH, Orton CG. Advocating for use of the ALARA principle in the context of medical imaging fails to recognize that the risk is hypothetical and so serves to reinforce patients' fears of radiation. Medical physics. 2017 Jan;44(1):3-6. https://doi.org/10.1002/mp.12012

[36] Dauer LT, Thornton RH, Hay JL, Balter R, Williamson MJ, St. Germain J. Fears, feelings, and facts: interactively communicating benefits and risks of medical radiation with patients. AJR Am J Roentgenol. 2011 Apr;196(4):756-61. https://doi.org/10.2214/AJR.10.5956

[37] Alotaibi M, Saeed R. Radiology nurses' awareness of radiation. J RadiolNurs. 2006 Mar 1;25(1):7-12. https://doi.org/10.1016/j.jradnu.2005.12.001

[38] Takanami R, et al. (2006) Houshasenshinryooyobihousyase nhibaku no bougonikansurukangoshi no chishikiinshiki no jittai: KangoKyoiku 47: 528-533 (in Japanese)

[39] Anim-Sampong S, Opoku SY, Addo P, Botwe BO. Nurses knowledge of ionizing radiation and radiation protection during mobile radiodiagnostic examinations. Educ. Res. 2015 Apr;6(3):39-49. http:/dx.doi.org/10.14303/er.2015.020

[40] Vaiserman A, Koliada A, Zabuga O, Socol Y. Health impacts of low-dose ionizing radiation: current scientific debates and regulatory issues. Dose-Response. 2018 Sep 18; 16(3): 1559325818796331.

https://doi.org/10.1177/1559325818796331

[41] Rose A, Rae WI. Personal Protective Equipment Availability and Utilization among Interventionalists. Saf Health Work. 2019 Jun 1;10(2):166-71. https://doi.org/10.1 016/j.shaw.2018.10.001 
[42] Partap A, Raghunanan R, White K, Seepaul T. Knowledge and practice of radiation safety among health professionals in Trinidad. SAGE Open Med. 2019 Apr;7:2050312119848 240. https://doi.org/10.1177/2050312119848240

[43] Evans KM, Bodmer J, Edwards B, Levins J, O’Meara A, Ruhotina M, Smith R, Delaney T, Hoffman-Contois R, Boccuzzo L, Hales H. An exploratory analysis of public awareness and perception of ionizing radiation and guide to public health practice in Vermont. J Environ Public Health. 2015 Apr 28; 2015. https://doi.org/10.1155/2015/476495

[44] Szarmach A, Piskunowicz M, Świętoń D, Muc A, Mockałło G, Dzierżanowski J, Szurowska E. Radiation safety awareness among medical staff. Pol. J. Radiol. 2015; 80:57. https://doi.org/10.12659/PJR.892758 